Yol.2 2Nn. I لanuari 2019

ISSN 2614-2775

e-ISSN 2621-8143

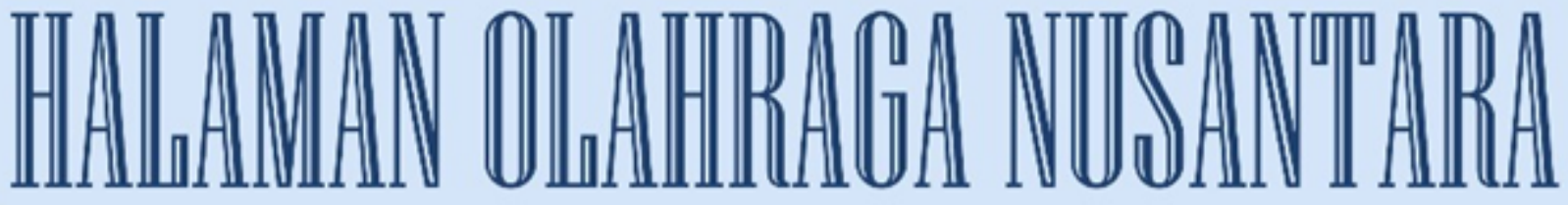

Surnal @lmu Xeolahragaan

Diterbitkan Oleh:

Program Studi Pendidikan Olahraga

Fakultas Keguruan dan Ilmu Pendidikan

Universitas PGRI Palembang

Jurnal

Volume Nomor Halaman Palembang ISSN/e-ISSN

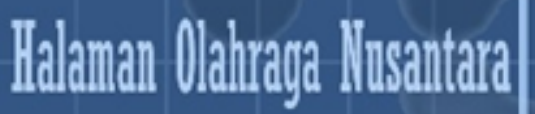

\begin{tabular}{l|l|l|l}
2 & 1 & $1-96$ & 2019
\end{tabular}




\section{Halaman Olahraga Nusantara}

Jurnal Ilmu Keolahragaan

Volume 2, Nomor 1, Januari 2019

Pelindung/Penasehat

Dr. H. Bukman Lian, M. M., M. Si.

Penanggung Jawab

Dr. Dessy Wardiah, M. Pd.

Ketua Dewan Redaksi

Farizal Imansyah, M. Pd.

Wakil Ketua Dewan Redaksi

Ilham Arvan Junaidi, M. Pd.

Sekretaris

Bayu Iswana, M. Pd.

Penyunting Pelaksana

Rafel Orlando, M. Pd.

Ardo Okilanda, M. Pd.

Daryono, M. Pd.

\section{Mitra Bestari}

Prof. Dr. A. Sofyan Hanif, M. Pd (Universitas Negeri Jakarta)

Dr. Sukirno (Universitas Sriwijaya)

Dr. Ronni Yenes, M. Pd (Universitas Negeri Padang)

Dr. Benny, M. Pd. (Universitas Negeri Makasar)

Dr. Putri Cicilia Kristina, M. Pd (Universitas PGRI Palembang)

\section{Tata Usaha}

M. Taheri Akbar, M. Pd.

Widya Handayani, S. Pd., M. Si.

Setting:

Dede Dwiansyah Putra, M. Pd.

Alamat Redaksi:

Prodi Pendidkan Olahraga Fakultas Keguruan Ilmu dan Pendidikan Universitas PGRI Palembang

Jl. Jendral A. Yani Lorong Gotong Royong 9/10 Ulu Palembang

Telp. 0711-510043, Fax. 0711-514782

e-mail jurnal: jurnalhonupgripalembang@gmail.com

e-mail : ardo.oku@univpgri-palembang.ac.id

website: univpgri-palembang.ac.id 
Halaman Olahraga Nusantara (Jurnal Ilmu Keolahragaan)

P-ISSN 2614-2775

Volume 2, No. 1, Januari 2019

E-ISSN 2621-8143

\section{DAFTAR ISI}

Hasil Penelitian

Halaman

Pengaruh Metode Rangkaian Bermain Terhadap Keterampilan Dasar Olahraga Panahan Siswa Ektrakulikuler Sit (Sekolah Islam Terpadu) Auladi Palembang

- Arisman

Penerapan Metode Bermain Dalam Meningkatkan Hasil Belajar Guling Depan (Forward Roll)

- Ruslan, M. Samsul Huda

Survei Tingkat Kesegaran Jasmani pada Peserta Ekstrakulikuler Sepakbola Di Sma Negeri 2 Oku

- Daryono

Kontribusi Daya Ledak Tungkai dan Keseimbangan Terhadap Kemampuan Lompat Jauh Murid Sd Negeri 139 Sinjai

- Adam Mappaompo

Survei Tingkat Kebugaran Jasmani Mahasiswa Pendidikan Olahraga Angkatan 2017 Stkip Pgri Bangkalan

- Heni Yuli Handayani .

Profil Delayed Onset Muscle Soreness (Doms) pada Mahasiswa Fik Unp Setelah Latihan Fisik

- Heru Syarli Lesmana

Perbedaan Pengaruh Latihan Menggunakan Karet dengan Menggunakan Dumbbell $1 \mathrm{Kg}$ Terhadap Kecepatan Pukulan Oi Tsuki

Chudan pada Atlet Karate Putra Perguruan Wadokai Dojo Sma Negeri 11 Medan Tahun 2017

- Pangondian Hotliber Purba $60-71$

Tinjauan Kondisi Fisik Atlet Sepakbola Kabupaten Kerinci Dalam

Rangka Persiapan Mengikuti Porprov Xxii Bungo Tebo 2018

- Palmizal, Wawan Junresti Daya, dan Sri Murniati

Aktivitas Jasmani dan Persepsi Gerak Anak Usia Dini

- Dian Pujianto 
Peningkatan Keterampilan Bermain Bolabasket Mahasiswa Melalui Latihan Aktifitas Maze Perkuliahan Permainan Bolabasket

- Ilham Arvan Junaidi dan Rury Rizhardy $88-96$ 


\title{
SURVEI TINGKAT KESEGARAN JASMANI PADA PESERTA EKSTRAKULIKULER SEPAKBOLA DI SMA NEGERI 2 OKU
}

\author{
Oleh: Daryono \\ (Dosen Universitas PGRI Palembang)
}

\begin{abstract}
Abstrak
Permasalahan yang akan di kaji dalam penelitian ini adalah bagaimanakah tingkat kesegaran jasmani siswa peserta ekstrakulikuler sepakbola di SMA Negeri 2 OKU. Adapun tujuan yang ingin dicapai dalam penelitian ini adalah untuk mengetahui tingkat kesegaran jasmani siswa peserta ekstrakurikuler sepakbola SMA Negeri 2 OKU yang berjumlah 18 orang. Dalam penelitian ini pengambilan sample menggunakan teknik total sampling yaitu seluruh siswa peserta ekstrakulikuler sepakbola di SMA Negeri 2 OKU. Variable dalam penelitian ini adalah tingkat kesegaran jasmani. Metode pengumpulan data menggunakan tes dan dokumentasi. Selanjutnya data yang diperoleh dianalisis dengan menggunakan analisis deskriptif prosentase. Setelah dilakukan analisis data mengenai kesegaran jasmani siswa peserta ekstrakulikuler sepakbola di SMA Negeri 2 OKU, 27,8 masuk dalam katogeri kurang, 61,1\% termasuk dalam kategori sedang, dan 11,1\% dalam kategori baik. Kesimpulan dari data tersebut adalah secara keseluruhan kebugaran jasmani masuk dalam kategori sedang. Saran dalam penelitian ini adalah perlu ditingkatkan kebugaran jasmani agar dapat meningkatkan prestasi.
\end{abstract}

Kata kunci: Kebugaran Jasmani, Sepak bola, SMA Negeri 2 OKU

\section{A PHYSICAL FITNESS LEVEL SURVEY AT FOOTBALL EXTRACURICULAR OKU 2 STATE HIGH SCHOOL}

\begin{abstract}
The problem that will be examined in this research is how the physical fitness level of the students of football extracurricular members at OKU 2 State High School. The aim to be achieved in this study was to determine the physical fitness level of the students who participated in the football extracurricular at SMA Negeri 2 OKU, amounting to 18 people. In this research, sample was taken using total sampling technique, that is all students who participated in extracurricular football at OKU 2 Public High School. The variable in this study is the level of physical fitness. Data collection methods using tests and documentation. Furthermore, the data obtained were analyzed using percentage descriptive analysis. After analyzing the data about the physical fitness of students participating in football extracurricular activities at SMA Negeri 2 OKU, 27.8 were included in the less-than-good category, 61.1\% included in the medium category, and $11.1 \%$ in the good category. The conclusion of the data is that
\end{abstract}


overall physical fitness is in the medium category. The suggestion in this study is that physical fitness needs to be improved in order to improve achievement.

Keywords : Physical Fitness, Football, OKU 2 State High School

\section{A. PENDAHULUAN}

Olahraga sepak bola merupakan olahraga yang memasyarakat yang digemari banyak kalangan, dari kalangan anak kecil sampai kalangan orang tua dan dimainkan dari pelosok desa sampai ke kota. Sepakbola merupakan permainan beregu, masing-masing regu terdiri dari sebelas pemain, dan salah satunya penjaga gawang. Permainan ini hampir seluruhnya dimainkan dengan menggunakan tungkai kecuali penjaga gawang yang diperbolehkan menggunakan lengannya didaerah tendangan hukumannya. Dalam perkembangannya permainan ini dapat dimainkan di luar lapangan (outdoor) dan di dalam ruangan tertutup (indoor). Sepakbola berkembang dengan pesat di kalangan masyarakat, karena permainan ini dapat dimainkan oleh laki- laki dan perempuan; anak-anak, dewasa; dan orang tua (Sucipto, dkk, 1999/2000:7)

Pada kehidupan nyata di masyarakat, sepakbola memang merupakan olahraga yang sangat popular dan digemari oleh semua strata atau golongan masyarakat. Oleh karena itu prestasi dan kesuksesan dalam sepakbola menjadi kritikan dan sebuah elemen yang sangat penting untuk diperhatika oleh pemerintah. Dalam upaya membina prestasi yang baik maka pembinaan harus dimulai dari pembinaan usia muda dan atlet muda berbakat sangat menentukan menuju tercapainya mutu prestasi optimal dalam cabang olahraga sepak bola. Bibit atlet yang unggul perlu pengolahan dan proses kepelatihan secara ilmiah, barulah muncul prestasi atlet semaksimal mungkin pada umur-umur tertentu. Atlet berbakat yang umurnya muda dapat ditemukan di sekolah-sekolah, klub, organisasi pemuda dan kampung-kampung.

Hakekat olahraga merupakan kegiatan fisik yang mengandung sifat permainan dan berisi perjuangan melawan diri sendiri atau dengan orang lain. Kegiatan olahraga meliputi gaya pertandingan, maka kegiatan itu harus dilaksanakan dengan semangat atau jiwa sportif. Pada olahraga kelompok mendorong manusia saling bertanding dalam suasana kegembiraan dan kejujuran. 
Olahraga memberi kemungkinan pada tercapainya rasa saling mengerti dan menimbulkan solidaritas serta tidak mementingkan diri sendiri. Olahraga juga dapat dijadikan alat pemersatu.

Dalam pembelajaran sepak bola, kita mengenal aspek-aspek yang perlu dikembangkan yaitu: (1) Pembinaan teknik (keterampilan) (2) Pembinaan fisik (kesegaran jasmani) (3) Pembinaan taktik (4) Kematangan juara (Soekatamsi, 1984:11). Dalam peningkatan kecakapan permainan sepakbola, keterampilan dasar erat sekali hubungannya dengan kemampuan koordinasi gerak fisik, taktik dan mental. Keterampilan dasar harus betul-betul dikuasai dan dipelajari lebih awal untuk mengembangkan mutu permainan yang merupakan salah satu faktor yang menentukan menang atau kalahnya suatu kesebelasan dalam suatu pertandingan.

Faktor-faktor yang mempengaruhi pencapaian sepak bola diantaranya ialah faktor fisik dan keterampilan teknik dasar permainan sepak bola para pemainnya. Oleh karena itu, seorang pemain yang tidak memiliki fisik dan keterampilan teknik dasar bermain sepak bola yang baik tidak mungkin akan menjadi pemain yang baik dan sulit untuk mencapai prestasi maksimal. Dengan melakukan latihan fisik dan keterampilan gerak dasar yang teratur dan sebaiknya dimulai sejak usia dini. Untuk meningkatkan kesegaran jasmanibiasanya pelatih memberikan latihan yang didalamnya mengandung beberapa aspek yang berhubungan dengan kesegaran jasmaniyang terdiri dari latihan kekuatan, kelentukan, kecepatan, kelincahan dan daya tahan.

Kegiatan ekstrakurikuler di SMA Negeri 2 OKU merupakan kegiatan yang sudah diprogram dengan kebutuhan yang diinginkan oleh sekolah. Adapun kegiatan ekstrakurikuler yang di adakan di SMA Negeri 2 OKU yaitu meliputi : ekstrakulikuler sepakbola, bolavoli, pencaksilat, dan pramuka. Kegiatan olahraga sepakbola merupakan bagian dari kegiatan ekstrakurikuler olahraga di SMA Negeri 2 OKU yang diselenggarakan pada hari senin dan kamis mulai dari pukul 15.30-17.30 WIB dengan dukungan fasilitas yang cukup memadai. Kegiatan ekstrakulikuler sepakbola diikuti oleh siswa kelas 1,2 dan 3. 
Ketertarikan peneliti dalam melakukan penelitian di SMA Negeri 2 OKU disebabkan oleh prestasi yang diperoleh tim sepakbola di SMA Negeri 2 OKU yang baik dalam pertandingan antar pelajar di kabupaten OKU. Pencapaian Prestasil Tim Sepakbola di SMA Negeri 2 OKU Tahun 2011-2014.

Tabel 1. Prestasi tim sepakbola SMA Negeri 2 OKU

\begin{tabular}{llll}
\hline No & Even Pertandingan & Waktu & Hasil \\
\hline 1 & LPI Kabupaten & 2011 & Juara I \\
\hline 2 & LPI Provinsi & 2011 & Raner Up \\
\hline 3 & LPI Kabupaten & 2012 & Juara I \\
\hline 4 & LPI Provinsi & 2012 & Raner Up \\
\hline 5 & Kejuaraan Umum & 2013 & 8 Besar \\
\hline 6 & Kejuaraan Umum & 2014 & 8 Besar \\
\hline
\end{tabular}

Dari data di atas dapat disimpulkan bahwa SMA Negeri 2 OKU memiliki tim ekstrakurikuler sepakbola yang baik dari segi prestasi. Hal ini sangat menarik ketika suatu sekolah yang tidak hanya unggul dalam bidang akademik melainkan juga dalam bidang olahraga yang membutuhkan waktu ekstra dan penanganan khusus dari seorang guru olahraga. Para siswa yang mengikuti kegiatan ekstrakurikuler sepakbola patut mendapatkan perhatian khusus mengenai bagaimana mereka mengatur jadwal belajar dan latihan karena jadwal latihan tentu akan membuat mereka letih pada malam harinya saat mereka akan belajar. Hal ini sebenarnya dapat mempengaruhi kemampuan fisik mereka dalam berlatih.

Kemampuan mereka melakukan teknik dasar tentu sangat dipengaruhi oleh perkembangan tubuh dan psikologis mereka sebagai seorang siswa smp. Kemampuan melakukan teknik dasar harus dilatih secara bertahap dan kontinyu sesuai usia dan kemampuan mereka. Berdasarkan latar belakang yang telah diuraikan di atas, kesegaran jasmani atau tingkat kesegaran jasmani merupakan hal yang sangat penting bagi seorang atlet, maka penulis ingin mengetahui tingkat kesegaran jasmani peserta ekstrakurikuler sepak bola SMA Negeri 2 OKU. 


\section{B. METODE PENELITIAN}

Metode penelitian merupakan syarat mutlak dalam suatu penelitian. Berbobot tidaknya suatu penelitian tergantung pada pertangung jawaban metodologi penelitiannya. Metode yang digunakan dalam penelitian ini adalah survey test. Survei adalah merupakan bagian dari study deskriptif yang bertujuan untuk mencari kedudukan atau status,fenomena (gejala) dan menemukan kesamaan status dengan cara membandingkan standart yang sudah di tentukan Suharsimi Arikunto (2006:90).

Menurut Suharsimi Arikunto (2006:116), variabel adalah gejala yang bervariasi dan menjadi objek penelitian. Sedangkan menurut Sugiyono (2007:2), variabel adalah suatu atribut atau sifat atau nilai dari orang, obyek atau kegiatan yang mempunyai variasi tertentu yang ditetapkan oleh peneliti untuk dipelajari dan ditarik kesimpulannya.Variabel dalam penelitian ini adalah tingkat kesegaran jasmani peserta ekstrakurikuler sepak bola SMA Negeri 2 OKU. Penelitian ini adalah jenis penelitian yang bersifat "kuantitatif" dan Penelitian Analisa yang dipergunakan dalam penelitian ini yaitu analisis statistik deskriptif persentase ,dalam penelitian ini digunakan untuk mendeskripsikan data tes kesegaran jasmani peserta ekstrakurikuler SMA Negeri 2 OKU.

Sugiyono (2007:115) menjelaskan bahwa populasi adalah wilayah generalisasi yang terdiri atas;objek/subjek yang mempunyai kuantitas dan karakteristik tertentu yang ditetapkan oleh peneliti untuk dipelajari dan kemudian ditarik kesimpulannya. Sedangkan Syaifuddin Azwar (2010: 77) menyatakan bahwa "populasi didefinisikan sebagai kelompok subjek yang hendak dikenai generalisasi hasil penelitian generalisasi yang terdiri atas objek atau subjek yang mempunyai kualitas dan karakteristik tertentu yang ditetapkan oleh peneliti untuk dipelajari dan kemudian disimpulkan”. Populasi adalah keseluruhan subjek penelitian (Arikunto, 2006:130). Populasi dalam penelitian ini adalah seluruh siswa ptra yang mengikuti ekstrakurikuler sepakbola di SMA N 2 OKU Sumatera Selatan yang berjumlah 18 Orang. Sampel adalah bagian dari jumlah dan karakteristik yang dimiliki oleh populasi (Sugiyono, 2011: 62). Sedang menurut 
Arikunto (2010: 174) berpendapat bahwa Sampel adalah sebagian atau wakil dari populasi yang diteliti. Penarikan sampel dalam penelitian ini menggunakan teknik total sampling, yaitu teknik pengambilan sampel dengan memakai seluruh populasi yang ada. Jadi populasi dalam penelitian ini adalah seluruh peserta ekstrakurikuler sepakbola SMA N 2 OKU yang berjumlah 18 Orang. Pengumpulan data dalam penelitian ini menggunakan teknik tes dan pengukuran. Adapun macam tes yang akan dilakukan dalam penelitian ini meliputi: (1) Lari 60 meter, (2) Gantung angkat tubuh 60 detik, (3) Baring duduk 60 detik, (4) Loncat Tegak, (5) Lari 1200 meter.

Analisa yang dipergunakan dalam penelitian ini yaitu analisis statistik deskriptif persentase, yaitu analisis statistik yang berfungsi untuk mendeskripsikan atau memberi gambaran terhadap obyek yang diteliti melalui data sampel atau populasi sebagaimana adanya yang dinyatakan dengan persen atau perseratus, tanpa melakukan analisis dan membuat kesimpulan yang berlaku untuk umum (Sugiyono, 2007: 29).

\section{HASIL DAN PEMBAHASAN}

Hasil analisis deskriptif kesegaran jasmanisecara keseluruhan pada siswa peserta ekstra kulikuler sepakbola di SMA Negeri 2 OKU dapat dilihat pada grafik berikut ini :

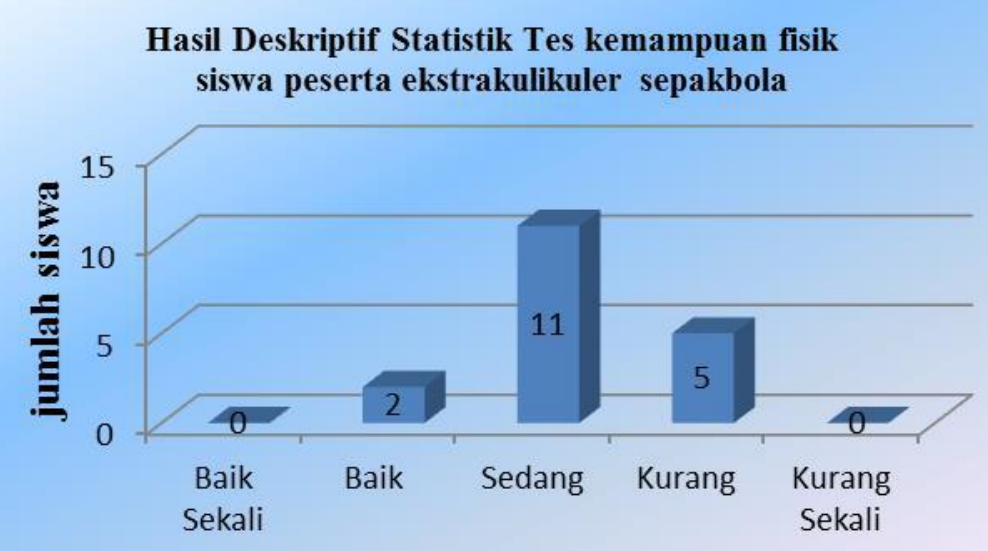


Berdasarkan grafik diatas maka dapat diketahui bahwa hasil tes kemampuan fisik pada siswa peserta ekstrakulikuler sepakbola di SMA Negeri 2 OKU keseluruhan terdapat 2 pemain yang memperoleh nilai baik, 11 pemain memperoleh nilai sedang dan 5 pemain memperoleh nilai kurang. Dari hasil diatas terlihat bahwa tidak terdapat pemain yang secara keseluruhan memiliki kesegaran jasmaniyang baik sekali atau kurang sekali. Sedangkan jika dilihat dari tingkat persentase sebagai berikut :

Tabel 1. Kondisi Fisik

\begin{tabular}{llllll}
\hline & & Frequency & Percent & Valid Percent & $\begin{array}{l}\text { Cumulative } \\
\text { Percent }\end{array}$ \\
\hline Valid & Kurang & 5 & 27,77 & 27,8 & 27,8 \\
& Sedang & 11 & 61,11 & 61,1 & 88,9 \\
& Baik & 2 & 11,11 & 11,1 & 100,0 \\
& Total & 18 & 100,0 & 100,0 & \\
\hline
\end{tabular}

Hasil penelitian tes kesegaran jasmani diketahui secara keseluruhan, sebagian besar siswa peserta ekstra kulikuler sepakbola di SMA Negeri 2 OKU dalam kategori sedang $61,1 \%, 27,8 \%$ dalam kategori kurang dan 11,1 dalam kategori baik.

Siswa yang memiliki kesegaran jasmani baik hanya $11,1 \%$ hal ini terjadi karena ada beberapa siswa yang ikuti latihan atletik sehingga memiliki kesegaran jasmaniyang baik, 61,1\% masuk dalam kategori sedang disebabkan karena sebagian besar siswa peserta ekstrakulikuler aktif ikut tim sepakbola di rumahnya, sehingga mempengaruhi kondisi fisiknya. 27,8\% siswa peserta ekstrakulikuler sepakbola memiliki kesegaran jasmani kurang hal tersebut dipengaruhi karena faktor kelelahan sehaingga hasil yang dicapai kurang maksimal, selain itu sebagian dari siswa peserta ekstrakulikuler masih kelas $\mathrm{X}$ sehingga kondisi fisiknya kurang baik.

Kesegaran jasmani merupakan salah satu factor yang mempengaruhi keberhasilan seorang pemain, karena dengan kesegaran jasmani yang baik seorang pemain sepakbola akan dapat memaksimalkan kemampuanya. untuk 
meningkatkan kesegaran jasmani seorang pemain harus berlatih dengan teratur dan sesuai dengan prosedur latihan. Latihan yang dilakukan harus berulang-ulang dan intervalnya makin meningkat.

\section{KESIMPULAN}

Berdasarkan hasil penelitian pada hasil penelitan dan pembahasan dapat diambil kesimpulan bahwa tingkat kesegaran jasmani siswa peserta ekstrakurikuler secara umum masuk dalam kategori sedang. Hal ini bisa dilihat dari masing-masing hasil tes dari Tes Kesegaran Jasmani Indonesia untuk remaja umur 16-19 tahun yang telah di paparkan dalam bab terdahulu.

\section{DAFTAR PUSTAKA}

Azwar, Saifuddin. 2010. Metode Penelitian. Yogyakarta: Pustaka Pelajar.

Sucipto dkk, 2000.Sepak Bola.Depdikbud: Dirjendikti

Sukatamsi. 1984. Teknik Dasar Bermain Sepak Bola. Solo: Tiga Serangkai

Suharsimi Arikunto.2006. Prosedur Penelitian: Suatu Pendekatan Praktik. Jakarta: PT. Rineka Cipta

Suharsimi Arikunto. 2010. Prosedur Penelitian Suatu Pendekatan Praktek. Jakarta : Rineka Cipta.

Sugiyono. 2007. Statistika untuk Penelitian. Bandung: Alfabeta

Sugiyono. 2011. Metode Penelitian Kuantitatif, Kualitatif dan R\&D. Bandung: Afabeta

Pusat Kesegaran Jasmani dan Rekreasi.2000. Tes Kesegaran Jasmani Indonesia Untuk Remaja Umur 16-19 Tahun. Jakarta : Pusat Kesegaran Jasmani dan Rekreasi Pusat 


\section{GAYA SELINGKUNG}

1. Jurnal Halaman Olahraga Nusantara menerbitkan karya ilmiah dan hasil penelitian dalam seluruh kajian ilmu keolahragaan, baik pendidikan, kepelatihan, dan lainya dalam pengembangan teori dan konsep yang belum pernah dipublikasikan. Jurnal ini memuat (1) kumpulan informasi baru, (2) hasil objektif dari suatu kajian ilmu keolahragaan, dan (3) rekomendasi.

2. Penulisan naskah menggunakan bahasa Indonesia secara benar. Panjang naskah antara 7-20 halaman, kertas ukuran quarto, diketik 1,5 spasi, tipe huruf Times New Roman, ukuran huruf 12, margin atas dan kiri 4 cm, kanan dan bawah $3 \mathrm{~cm}$.

3. Naskah ditulis dengan sistematika dan ketentuan sebagai berikut.

a. Judul: ditulis dengan singkat, padat, terdiri dari 5-15 kata, dan menggunakan bahasa Indonesia, harus mencerminkan substansi keilmuan yang diuraikan pada batang tubuh artikel. Judul utama (main title) dan anak judul (subtitle) dipisahkan dengan dua titik. Judul artikel dicetak 15 mm dibawah tepi atas, dengan huruf capital-kecil tebal. Judul subbab peringkat 1 dicetak capital semua, rata tepi kiri, tebal, peringkat 2 dicetak capital kecil, rata tepi kiri, tebal; peringkat 3 dicetak kapital-kecil, rata tepi kiri, miring-tebal.

b. Nama penulis: Nama penulis artikel ditulis tanpa disertai gelar akademik atau gelar apapun. Nama lengkap dengan gelar akademik boleh ditulis disebelah bawah halaman pertama artikel. Nama lembaga tempat bekerja penulis juga dibuat sebagai catatan kaki dihalaman pertama. Jika lebih dari tiga penulis, hanya penulis utama saja yang dicantumkan dibawah judul; nama penulis lain ditulis dalam catatan kaki.

c. Abstrak artikel kajian ilmiah/ konseptual adalah ringkasan dari isi artikel yang dituangkan secara padat menggunakan bahasa Indonesia dan bahasa inggris. Abstrak hasil penelitian memuat masalah atau tujuan, metode, dan hasil penelitian. Abstrak terdiri dari 100-300 kata yang disusun dalam satu 
paragraph dengan format esei bukan enumeratif, dan diketik dengan spasi tunggal serta dengan format yang lebih sempit dari teks utama.

d. Kata Kunci terdiri dari 3-5 kata, yaitu istilah-istilah yang mewakili ide atau konsep dasar yang dibahas dalam penulisan karya ilmiah. Kata kunci lazimnya berupa kata dasar atau kata yang berdiri sendiri (tunggal) bukan rangkaian kata.

e. Naskah hasil penulisan ditulis dengan urutan (1) judul, (2) nama penulis, (3) abstrak, (4) kata kunci, (5) bagian pendahuluan yang harus di akhiri dengan rumusan singkat (1-2 kalimat) tentang hal-hal pokok yang akan dibahas dan tujuan dari pembahasan. Untuk artikel hasil penelitian berisi (a) rumusan masalah, (b) tujuan, dan (c) deskripsi singkat mengenai kerangka pemikiran dalam pendahuluan, (6) isi memuat (a) metode penelitian, (b) hasil penelitian, dan (c) pembahasan. (8) simpulan dan saran, (9) daftar pustaka.

f. Naskah diluar hasil penelitian ditulis dengan urutan (1) judul, (2) nama penulis, (3) abstrak, (4) kata kunci, (5) pendahuluan yang memuat latar belakang dan rumusan masalah, (6) isi, (7) simpulan, dan (8) daftar pustaka.

g. Table dan gambar/ bagan di usahakan dicetak dalam satu halaman, nomor dan judul table dan gambar dicetak di atas table dengan huruf tebal. Isi dalam table dicetak dengan huruf normal (tidak tebal). Table hanya menggunakan garis horizontal (horizontal border)

h. Penulisan daftar pustaka

1) Buku ditulis dengan urutan: (a) nama akhir, (b) koma, (c) nama depan penulis, (d) titik, (e) tahun penerbitan, (f) titik, (g) judul buku dalam huruf miring, (h) titik, (i) edisi jika ada, (j) titik, (k) kota penerbitan, (l) titik dua, (m) nama penerbit, dan (n) titik.

2) Artikel ditulis dengan urutan: (a) nama akhir, (b) koma, (c) nama depan penulis, (d) titik, (e) tahun penerbitan, (f) titik, (g) tanda petik dua, (h) judul artikel, (i) titik, (j) tanda petik tutup, (k) nama jurnal dalam cetak miring, (l) volume, (m) nomor, dan (n) titik. Apabila artikel diterbitkan 
disuatu buku, tulis kata "dalam" sebelum nama editor buku tersebut, dan buku harus ditulis didalam daftar pustaka.

3) Skripsi, thesis, atau disertasi ditulis dengan urutan: (a) nama akhir, (b) koma, (c) nama depan penulis, (d) titik, (e) tahun, (f) titik, (g) judul dalam huruf miring, (h) skripsi/thesis/disertasi pada (nama perguruan tinggi yang bersangkutan), (i) nama kota, (j) titik dua, (k) tulisan "tidak diterbitkan", dan (1) titik. 